\title{
El periodismo televisivo, las fuentes periodísticas y la comunicación por redes sociales en el noticiero de televisión
}

\author{
Recibido: 02 de septiembre de 2015 \\ Aceptado: 01 de abril de 2016 \\ Publicado: 30 de noviembre de 2016
}

Resumen: La presente investigación permite conocer la relación entre el periodismo televisivo, las fuentes periodísticas y la comunicación por redes sociales y explica la forma en que la producción del noticiero de televisión se nutre por el contacto con las fuentes que, a su vez, han cambiado gracias al uso de plataformas virtuales como Facebook y Twitter. Es un estudio no experimental, aplicativo, descriptivo, correlacional y multivariable, que abordó una muestra de 30 periodistas del noticiero "ATV Noticias" de la Empresa Andina de Radiodifusión de la ciudad de Lima, Perú. Entre las principales conclusiones, se comprobó que la masificación de la Internet y las redes sociales han afectado la producción de los contenidos audiovisuales del noticiero, desde la selección de los temas que abordarán las noticias, el contacto con las fuentes periodísticas y la labor del reportero de televisión, hasta la elaboración del minutado y la retroalimentación generada en el entorno virtual de las redes sociales.

Palabras clave: Periodismo, televisión, producción periodística, noticiero, información audiovisual, fuentes periodísticas, redes sociales, Facebook, Twitter, interactividad.

Abstract: This paper is aimed to understand the relation between Television Journalism,
journalistic sources and social network communication. Also, it explains how television
news production benefits of the contact with journalistic sources, which have changed
since the use of virtual platforms such as Facebook and Twitter. This is a non experimental,
applicative, descriptive, correlative and multivariable study. The sample consisted in
thirty journalists from television news program "ATV Noticias" (Andina de Radiodifusion
Company, Lima, Peru). The research concluded that the frequent use of Internet and Social
Networks impacted television news programs. This happens during television production 
process: themes selection, contact with journalistic sources and reporters work, until the outline and the feedback generated by the Social Networks.

Key words: Journalism, Television, Newsmaking, News, Audiovisual Information, Journalistic Sources, Attribution, Social Network, Facebook, Twitter, Interactivity.

\section{Introducción}

Las ciencias de la comunicación se encuentran, hoy más que nunca, en constante cambio. Sus profesionales afrontan las rutinas productivas a medida que estas se adaptan a la convergencia multimedia, las herramientas online y la interactividad innata de la Internet. Desde la profesionalización de la labor informativa (a raíz de la aparición de la imprenta en el siglo $\mathrm{XV}$ ), hasta la instauración de los ordenadores personales en las redacciones de los medios de comunicación, el periodismo se ha enriquecido de la modernidad y las tecnologías de la información.

La prensa, que llegó a masificar métodos hasta hoy utilizados como el modelo de la "pirámide invertida", sirvió de base cuando se desarrollaron los primeros noticieros transmitidos vía ondas hertzianas. A su vez, los cánones de la narración de la noticia oral se emplearon con la llegada de la televisión. Entonces, el periodismo descubrió el lenguaje audiovisual gracias a la llegada de los equipos ENG (Electronic News Gathering o "producción electrónica de informativos") que permitían la grabación de imágenes en exteriores mediante una Camcorder, cámara con grabadora incorporada que revolucionó el periodismo televisivo a nivel mundial, que en el Perú empezó a inundar las viviendas de los televidentes en los ochentas.

Una revolución similar (pero a escalas antes desconocidas e incalculables) es la que se viene presentando en la actualidad gracias a las tecnologías de la información y los alcances del metamedio Internet. A las imágenes en movimiento se suma la participación de los usuarios y de las fuentes periodísticas en las redes sociales, cuya dinámica especial amerita ser abordada de forma científica dado que ha ingresado raudamente en la rutina productiva de las noticias, cuestionando así la labor de los medios de comunicación tradicionales. El periodismo televisivo no ha estado exento de estas modificaciones en las relaciones sociales, la comunicación y la rutina laboral. Al respecto, Pérez (2010: 64) sostiene que:

“conforme al ritmo de los tiempos, el mundo digital penetró en las cadenas de televisión mucho antes de que sus emisiones fueran completamente digitales. Las redacciones comenzaron tímidamente a informatizarse a partir de los años 80 , cuando los ordenadores personales sustituyeron a las viejas máquinas de escribir, convirtiéndose en unas nuevas máquinas de escribir algo más sofisticadas".

Con la llegada de los ordenadores personales a las redacciones de los noticieros de las principales cadenas de televisión, fue inminente la irrupción de la Internet y posteriormente la aplicación de chats, correos electrónicos y la navegación en la World Wide Web dentro de la rutina periodística. Sin embargo, desde la transmisión de los primeros noticieros 
en televisión, productores y directores periodísticos han tratado de asentar la labor de producción informativa a través del contacto con las fuentes periodísticas. Se cuenta desde entonces con un sistema de trabajo ya institucionalizado donde el periodista debe buscar, seleccionar, valorar, construir y difundir noticias apoyándose en la importancia de sus fuentes periodísticas. Esta radica en que las fuentes periodísticas (ya sean oficiales o no oficiales) brindan las primeras luces en el proceso de confección de la noticia o hasta se convierten en las protagonistas principales de las mismas.

Al ser sometidas a procesos de selección y valoración, las fuentes periodísticas son las responsables de la credibilidad y el peso informativo de un noticiero de televisión y están presentes en todo el proceso de producción de un noticiero. Mientras las ediciones centrales de los noticieros de televisión continúan cobrando importancia en el proceso de información de los pobladores de un país o región, la comunicación por redes sociales también va ganando terreno. Ciudadanos, políticos y periodistas empiezan a crear y manejar cuentas y perfiles en redes sociales como Facebook y Twitter, que tienen sus propios esquemas de comunicación.

Gracias a este fenómeno, el contacto del periodista con sus fuentes de información está cambiando en los últimos años en diversos aspectos. La cantidad de fuentes a las que tiene acceso el periodista ha aumentado considerablemente. Además, las características propias de estos nuevos medios de comunicación dentro de la Internet permiten que el contacto con las fuentes esté cargado de inmediatez e interactividad. Por ejemplo, una agencia de noticias puede lanzar una información de último minuto tanto en su cuenta de Facebook como de Twitter. De forma inmediata, periodistas y usuarios que estén conectados a la red de esta agencia de noticias en particular tendrán conocimiento de la información propalada. A continuación, todos aquellos que reciban dicha información podrán responder y expresar sus opiniones al respecto. Todo este proceso de emisión-recepción y retroalimentación en pocos minutos. Respecto a la comunicación en Twitter, por ejemplo, Mayoral (2013: 139) indica que:

"la nueva escritura periodística en Twitter se fundamenta en la brevedad (no más de 140 caracteres por tuit), pero sobre todo en la hipertextualidad y en la interactividad. Un breve enunciado permite remitir al lector a otro texto, a una fotografía o a un vídeo. Al mismo tiempo, y por la propia naturaleza de las redes, ese enunciado invita a los lectores a interactuar: respondiendo, retuiteando, señalándolo como favorito... Algo similar ocurre en otras redes sociales. La razón de ser de estas nuevas herramientas comunicativas parece íntimamente ligada a la interacción”.

Por ende, el uso de este nuevo canal para el intercambio de datos ha cobrado importancia en el periodismo televisivo y la producción de noticias en el formato audiovisual: desde el criterio de selección de noticias y la búsqueda de las mismas, hasta el proceso de investigación periodística y cobertura informativa por parte de los reporteros de televisión y su contacto directo con las fuentes. El proceso de creación de informes para un noticiero de televisión se inicia con la búsqueda y selección de noticias. En esta etapa, los periodistas encargados de la misma emplean también la comunicación por redes sociales para monitorear temáticas, encontrar denuncias y contactar a las personalidades implicadas en este tipo de hechos. 
Posteriormente, son los reporteros de televisión quienes se encargan de la cobertura de los hechos que formarán parte del noticiero central de su canal de televisión. Durante esta fase, muchos de ellos cubren acontecimientos de los que se está hablando en redes sociales o que, inclusive, han sido generados por usuarios en Facebook y Twitter horas antes. En otros casos, los reporteros se encargan de difundir las noticias que vienen cubriendo para sus respectivos noticieros, también instalados en las redes sociales. De esta forma, dan un adelanto a sus seguidores en Internet de lo que podrán encontrar en la edición central del informativo de televisión.

Debido a la interactividad propia de las redes sociales, durante todo el proceso de producción de un noticiero, los usuarios de Facebook y Twitter pueden contactarse con los periodistas para brindar datos o hasta valorar las noticias y propagar sus opiniones, convirtiéndose así (según la coyuntura) en nuevas fuentes periodísticas. Existen otros escenarios en los cuales las declaraciones de agentes políticos realizadas en sus propias cuentas de redes sociales (como Facebook y Twitter) cobran vida propia por su relevancia y, por ello, se elaboran noticias sólo con lo expresado en redes sociales; noticias que finalmente se incluyen en la pauta del informativo televisivo. En otras palabras, las discusiones que se suscitan en el mundo virtual de las redes sociales se convierten en noticia y llegan a miles de hogares a través de los noticieros de televisión.

\section{Objetivos}

El objetivo principal de la investigación es conocer de qué manera el periodismo televisivo se relaciona con las fuentes periodísticas y la comunicación por redes sociales (Facebook y Twitter) en el noticiero "ATV Noticias" de la empresa Andina de Radiodifusión. Es menester de esta investigación presentar los mecanismos en los cuales estas tres variables se conjugan en el entorno de producción de contenidos de un noticiero de televisión.

De manera específica, se pretende determinar la relación existente entre el periodismo televisivo y las fuentes periodísticas en el mencionado noticiero, dado que (a causa de la vorágine de las tecnologías de la información) el contacto directo con las fuentes de información, que desde sus inicios impone el periodismo televisivo, podría haberse visto afectado.

Asimismo, la investigación permite establecer de qué manera el periodismo televisivo se relaciona con la comunicación por redes sociales en el noticiero "ATV Noticias", tomando en consideración los métodos de intercambio de información propios de las plataformas virtuales Facebook y Twitter, además de la intención de sus usuarios de mantener relaciones comunicacionales en estas redes sociales.

\section{Metodología}

\subsection{Diseño metodológico}

Para responder a los problemas de investigación planteados y contrastar las hipótesis de investigación formuladas, se seleccionó el diseño no experimental, dado que no se 
manipulan las variables. Asimismo, se trata de una investigación de corte transversal, porque se aplicará el instrumento en una sola ocasión; y aplicativa debido a que se hará uso de los conocimientos ya existentes como teorías, enfoques, principios en cada variable de estudio.

En cuanto al nivel de la investigación, es descriptiva, porque se descubrirán las características relevantes de cada variable; y correlacional dado que se medirá la correlación entre las tres variables presentadas. A su vez, es multivariada porque se emplean más de dos variables: periodismo televisivo, fuentes periodísticas y comunicación por redes sociales.

Los métodos científicos elegidos para la demostración de las hipótesis son los siguientes: inductivo, porque de la verdad particular se obtiene la verdad general; deductivo, porque de la verdad general se obtiene la verdad particular; analítico, porque se desintegrará la realidad estudiada en sus partes componentes para ser investigadas a profundidad y establecer la relación causa-efecto entre las variables objeto de investigación; estadístico, porque se utilizarán herramientas estadísticas para arribar a conclusiones y recomendaciones.

\subsection{Diseño muestral}

\subsubsection{Población}

La población correspondiente a esta investigación es finita, ya que la cantidad de unidades de análisis es conocida y menor a 100,000. El conjunto de elementos o sujetos a los cuales se les realizará las mediciones poseen características, propiedades, cualidades y atributos homogéneos, es decir que dichas unidades de análisis son representativas. La población está conformada por 30 unidades de análisis, periodistas del noticiero "ATV Noticias" de la empresa Andina de Radiodifusión, distrito San Isidro, ciudad de Lima, Perú.

\subsubsection{Muestra}

La cantidad de unidades de análisis correspondientes a la muestra es equitativa a la población por criterio o conveniencia del investigador, respetando el muestreo no probabilístico. La muestra está conformada por 30 unidades de análisis, periodistas del noticiero "ATV Noticias" de la empresa Andina de Radiodifusión, distrito de San Isidro, ciudad de Lima, Perú.

\subsection{Descripción de los instrumentos}

El instrumento empleado fue el cuestionario, elaborado a partir de un conjunto de preguntas desprendidas de la siguiente operacionalización cualitativa de variables realizada por el investigador. 
Figura 1: Operacionalización cualitativa de variables.

\begin{tabular}{|c|c|c|c|c|}
\hline VARIABLES & $\begin{array}{l}\text { DIMEN- } \\
\text { SIONES }\end{array}$ & $\begin{array}{l}\text { INDICA- } \\
\text { DORES }\end{array}$ & & ÍTEMS O REACTIVOS \\
\hline \multirow{14}{*}{ 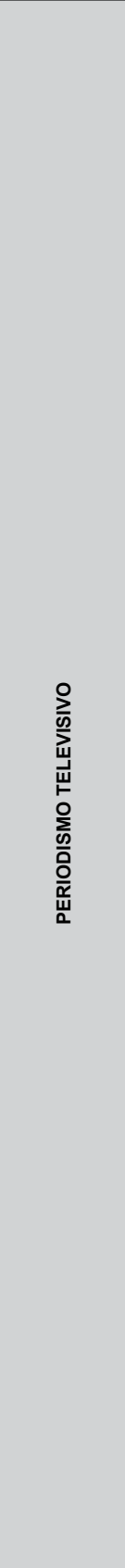 } & \multirow{6}{*}{$\begin{array}{l}\text { Género } \\
\text { informativo: } \\
\text { noticiero }\end{array}$} & \multirow{4}{*}{$\begin{array}{l}\text { Selección de } \\
\text { noticias }\end{array}$} & Políticas & $\begin{array}{l}\text { ¿Está Ud. de acuerdo en que la selección de noticias } \\
\text { POLITICAS se ve influenciada por la comunicación por } \\
\text { redes sociales? }\end{array}$ \\
\hline & & & Locales & $\begin{array}{l}\text { ¿Está Ud. de acuerdo en que la selección de noticias } \\
\text { LOCALES se ve influenciada por la comunicación por } \\
\text { redes sociales? }\end{array}$ \\
\hline & & & Policiales & $\begin{array}{l}\text { ¿Está Ud. de acuerdo en que la selección de noticias } \\
\text { POLICIALES se ve influenciada por la comunicación por } \\
\text { redes sociales? }\end{array}$ \\
\hline & & & Sociales & $\begin{array}{l}\text { ¿Está Ud. de acuerdo en que la selección de noticias } \\
\text { SOCIALES se ve influenciada por la comunicación por } \\
\text { redes sociales? }\end{array}$ \\
\hline & & \multirow{2}{*}{$\begin{array}{l}\text { Valoración } \\
\text { de noticias }\end{array}$} & Jerarquización & $\begin{array}{l}\text { ¿La JERARQUIZACIÓN de las noticias que se incluirán en } \\
\text { el noticiero considera como referencia los temas de mayor } \\
\text { impacto en las redes sociales? }\end{array}$ \\
\hline & & & Pauta & $\begin{array}{l}\text { ¿La PAUTA final del noticiero incluye noticias que se han } \\
\text { elaborado empleando insumos (comentarios, fotografías, } \\
\text { videos) publicados en las redes sociales? }\end{array}$ \\
\hline & \multirow{4}{*}{$\begin{array}{l}\text { Investigación } \\
\text { periodística }\end{array}$} & \multirow{2}{*}{$\begin{array}{l}\text { Documenta- } \\
\text { ción } \\
\text { audiovisual }\end{array}$} & Archivo & $\begin{array}{l}\text { ¿Cree Ud. que mediante las publicaciones en redes } \\
\text { sociales el periodista accede a material audiovisual que } \\
\text { le permite identificar ARCHIVO sobre el tema materia de } \\
\text { cobertura? }\end{array}$ \\
\hline & & & Selección & $\begin{array}{l}\text { ¿La SELECCIÓN de material audiovisual a emplear para } \\
\text { el desarrollo de una nota informativa puede nutrirse con los } \\
\text { videos compartidos en redes sociales? }\end{array}$ \\
\hline & & \multirow{2}{*}{$\begin{array}{l}\text { Documen- } \\
\text { tación } \\
\text { periodística }\end{array}$} & Background & $\begin{array}{l}\text { ¿Considera Ud. que durante el proceso de documentación } \\
\text { periodística el seguimiento a diversas cuentas en las } \\
\text { redes sociales permite al periodista conseguir mayor } \\
\text { BACKGROUND del tema materia de cobertura? }\end{array}$ \\
\hline & & & Acceso a las noticias & $\begin{array}{l}\text { ¿Las redes sociales facilitan que el periodista obtenga } \\
\text { mayor ACCESO A LAS NOTICIAS sobre el tema materia } \\
\text { de cobertura? }\end{array}$ \\
\hline & \multirow{4}{*}{$\begin{array}{l}\text { Acción } \\
\text { reporteril }\end{array}$} & \multirow{2}{*}{$\begin{array}{l}\text { Cobertura } \\
\text { informativa }\end{array}$} & Registro de imágenes & $\begin{array}{l}\text { ¿EI REGISTRO DE IMÁGENES en el proceso de cobertura } \\
\text { informativa toma en cuenta el material audiovisual } \\
\text { previamente compartido en las redes sociales? }\end{array}$ \\
\hline & & & Entrevistas & $\begin{array}{l}\text { ¿Está Ud. de acuerdo en que las ENTREVISTAS } \\
\text { desarrolladas por el periodista durante el proceso de } \\
\text { cobertura informativa se ven influenciadas por las } \\
\text { opiniones y publicaciones vertidas en Twitter por agentes } \\
\text { políticos? }\end{array}$ \\
\hline & & \multirow[b]{2}{*}{ Redacción } & Guión & $\begin{array}{l}\text { ¿Está Ud. de acuerdo en que durante la redacción del } \\
\text { GUIÓN de la nota informativa, el reportero debe incluir las } \\
\text { declaraciones de las fuentes publicadas en redes sociales? }\end{array}$ \\
\hline & & & Concisión & $\begin{array}{l}\text { ¿Está Ud. de acuerdo en que durante la redacción de } \\
\text { la nota informativa, el reportero debe regirse bajo la } \\
\text { CONCISIÓN propia del periodismo televisivo? }\end{array}$ \\
\hline
\end{tabular}




\begin{tabular}{|c|c|c|c|c|}
\hline \multirow{10}{*}{ 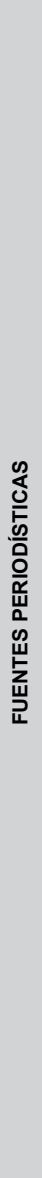 } & \multirow{6}{*}{$\begin{array}{l}\text { Tipos de } \\
\text { fuentes }\end{array}$} & \multirow{2}{*}{$\begin{array}{l}\text { Agencias } \\
\text { de noticias }\end{array}$} & Nacionales & $\begin{array}{l}\text { ¿Está Ud. de acuerdo en que el contacto con las } \\
\text { agencias de noticias NACIONALES es más directo } \\
\text { gracias a la comunicación por redes sociales? }\end{array}$ \\
\hline & & & Internacionales & $\begin{array}{l}\text { ¿Está Ud. de acuerdo en que el contacto con las } \\
\text { agencias de noticias INTERNACIONALES es más } \\
\text { directo gracias a la comunicación por redes sociales? }\end{array}$ \\
\hline & & \multirow{2}{*}{$\begin{array}{l}\text { Fuentes } \\
\text { oficiales }\end{array}$} & Instituciones & $\begin{array}{l}\text { ¿Las informaciones vertidas por las INSTITUCIONES } \\
\text { públicas o privadas en sus cuentas de redes sociales } \\
\text { pueden ser empleadas como declaraciones oficiales } \\
\text { respecto a un tema específico? }\end{array}$ \\
\hline & & & Políticos & $\begin{array}{l}\text { ¿Las publicaciones de los personajes POLÍTICOS en } \\
\text { sus cuentas en redes sociales pueden generar noticias } \\
\text { que tras ser desarrolladas forman parte de la pauta del } \\
\text { noticiero? }\end{array}$ \\
\hline & & \multirow{2}{*}{$\begin{array}{l}\text { Fuentes } \\
\text { particulares }\end{array}$} & Protagonistas & $\begin{array}{l}\text { ¿Considera Ud. que el contacto con los } \\
\text { PROTAGONISTAS de los hechos que hacen noticia se } \\
\text { facilita gracias a la comunicación por redes sociales? }\end{array}$ \\
\hline & & & Testigos & $\begin{array}{l}\text { ¿Está Ud. de acuerdo en que el material audiovisual } \\
\text { publicado en redes sociales por los TESTIGOS puede } \\
\text { convertirse en un insumo para la nota informativa? }\end{array}$ \\
\hline & \multirow{4}{*}{ Atribución } & \multirow[b]{2}{*}{ Verificación } & Contraste & $\begin{array}{l}\text { ¿Cree Ud. que la comunicación por redes facilita el } \\
\text { CONTRASTE de la información que brindan las fuentes } \\
\text { periodísticas? }\end{array}$ \\
\hline & & & Identificación & $\begin{array}{l}\text { ¿Considera Ud. que el acceso a la información que } \\
\text { publican las fuentes periodísticas en sus cuentas } \\
\text { personales de redes sociales facilita su verificación e } \\
\text { IDENTIFICACIÓN? }\end{array}$ \\
\hline & & \multirow{2}{*}{$\begin{array}{l}\text { Credibi- } \\
\text { lidad }\end{array}$} & Diversidad & $\begin{array}{l}\text { ¿Considera Ud. que la DIVERSIDAD de fuentes } \\
\text { periodísticas consignadas en una nota informativa dota } \\
\text { de credibilidad a la misma? }\end{array}$ \\
\hline & & & Equilibrio & $\begin{array}{l}\text { ¿Está Ud. de acuerdo en que el EQUILIBRIO entre las } \\
\text { declaraciones de las diversas fuentes vinculadas en una } \\
\text { noticia dota de credibilidad a la información? }\end{array}$ \\
\hline
\end{tabular}




\begin{tabular}{|c|c|c|c|c|}
\hline \multirow{12}{*}{ 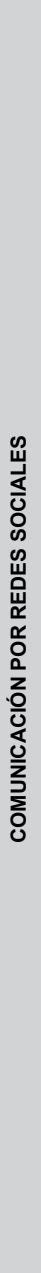 } & \multirow{6}{*}{ Facebook } & \multirow{2}{*}{ Perfiles } & Personales & $\begin{array}{l}\text { ¿Está Ud. de acuerdo en que los perfiles PERSONALES } \\
\text { de Facebook de los personajes involucrados en una noticia } \\
\text { se pueden emplear como fuente de información? }\end{array}$ \\
\hline & & & Cuentas oficiales & $\begin{array}{l}\text { ¿Considera que el periodista debe revisar las CUENTAS } \\
\text { OFICIALES en Facebook de las Instituciones Públicas } \\
\text { y privadas implicadas en el hecho materia de cobertura } \\
\text { informativa? }\end{array}$ \\
\hline & & \multirow{2}{*}{ Interactividad } & Retroalimentación & $\begin{array}{l}\text { ¿La RETROALIMENTACIÓN generada en Facebook sobre } \\
\text { un tema específico aporta datos extra para el periodista } \\
\text { que cubre dicha información? }\end{array}$ \\
\hline & & & Comentarios & $\begin{array}{l}\text { ¿Está Ud. de acuerdo en que los COMENTARIOS vertidos } \\
\text { en las publicaciones de Facebook pueden convertirse en } \\
\text { nuevas informaciones? }\end{array}$ \\
\hline & & \multirow{2}{*}{ Privacidad } & Fotografías & $\begin{array}{l}\text { ¿Las FOTOGRAFÍAS que comparte el protagonista } \\
\text { o testigo de un hecho en Facebook se convierten en } \\
\text { elementos que el periodista agrega a la noticia? }\end{array}$ \\
\hline & & & Publicaciones & $\begin{array}{l}\text { ¿Las PUBLICACIONES sobre denuncias que realizan } \\
\text { usuarios de Facebook pueden convertirse en noticia? }\end{array}$ \\
\hline & \multirow{6}{*}{ Twitter } & \multirow{2}{*}{ Inmediatez } & Concisión & $\begin{array}{l}\text { ¿Considera Ud. que la CONCISIÓN de los mensajes de } \\
\text { Twitter genera que estos tengan mayor impacto al ser } \\
\text { agregados a una nota periodística tras ser publicados por } \\
\text { las fuentes vinculadas al hecho? }\end{array}$ \\
\hline & & & Actualización & $\begin{array}{l}\text { ¿Las ACTUALIZACIONES constantes de los mensajes de } \\
\text { Twitter permiten que el reportero obtenga datos de primera } \\
\text { mano de forma inmediata? }\end{array}$ \\
\hline & & \multirow{2}{*}{$\begin{array}{l}\text { Hipertextua- } \\
\text { lidad }\end{array}$} & Multimedialidad & $\begin{array}{l}\text { ¿La MULTIMEDIALIDAD de los mensajes de Twitter facilita } \\
\text { que el periodista acceda a más datos, artículos, videos y } \\
\text { fotografías respecto al tema materia de cobertura? }\end{array}$ \\
\hline & & & Profundidad & $\begin{array}{l}\text { ¿Cree Ud. que la PROFUNDIDAD propia del hipertexto } \\
\text { en Twitter genera que el periodista entre en contacto con } \\
\text { nuevas fuentes? }\end{array}$ \\
\hline & & \multirow{2}{*}{ Interactividad } & Retroalimentación & $\begin{array}{l}\text { ¿La RETROALIMENTACIÓN propia de Twitter sirve como } \\
\text { orientación para el periodista al momento de evaluar el } \\
\text { impacto de las noticias? }\end{array}$ \\
\hline & & & Hashtags & $\begin{array}{l}\text { ¿Los HASHTAG en Twitter sirven como fuente de } \\
\text { información para que el periodista indague en el clima de } \\
\text { opinión generado respecto a un tema específico? }\end{array}$ \\
\hline
\end{tabular}

Fuente: Elaboración propia.

A partir de los ítems o reactivos se elaboró el cuestionario aplicado a la muestra. Para determinar la validez del instrumento se utilizó la prueba de juicio de expertos, la cual fue procesada mediante la fórmula de coeficiente de validez Aiken. En tanto, para determinar la confiabilidad del instrumento se utilizó el coeficiente Alfa de Cronbach.

\section{Hipótesis}

La hipótesis principal señala que el periodismo televisivo se relaciona significativamente con las fuentes periodísticas y la comunicación por redes sociales (Facebook y Twitter) en el noticiero "ATV Noticias". Dicha hipótesis se formuló luego de analizar los contenidos del mencionado telediario, que incluye noticias desarrolladas sobre la base de denuncias 
propagadas en cuentas personales de Facebook, además de noticias de índole político donde se muestran publicaciones de Twitter de agentes del gobierno o personajes relacionados a la coyuntura política. Inclusive, el noticiero se nutre de fotografías y videos compartidos en cuentas de redes sociales para ilustrar informaciones de carácter social o policial. Esta tendencia actual se ha propagado entre los diversos informativos de la televisión peruana. Por ende, el caso de "ATV Noticias" puede replicarse en otros telediarios.

\section{Marco teórico}

\subsection{Periodismo televisivo: el noticiero como estandarte}

Para comprender los cambios que sufren los telediarios a raíz de la convergencia multimedia y las tecnologías de la información, es necesario remontarse a la acepción del noticiero en formato audiovisual y los procesos que se abordan para otorgar el acontecer noticioso a los miembros de una determinada comunidad. Marín (2006: 83) sostiene que los noticieros son "producciones más comunes y estandarizadas [...] Su cometido es informar puntualmente sobre la actualidad, facilitando los sonidos (básicamente declaraciones) y las imágenes que proporcionen el conocimiento más completo de lo que haya sucedido". Precisamente, el noticiero es la fórmula estándar en televisión para emitir noticias y fue concebido dentro del periodismo televisivo como el formato que (mediante breves notas informativas) presenta al televidente un resumen de lo acontecido durante el día, basándose de manera primordial en las imágenes previamente captadas de los hechos narrar.

Este reinado absoluto de las imágenes en el periodismo audiovisual genera que el noticiero se haya convertido en la plataforma tradicional ideal para incluir material obtenido de las redes sociales, sobre todo cuando las tendencias informativas actuales siguen los cánones del infoentretenimiento, un género híbrido de la televisión actual que combina información y entretenimiento; en el cual la expresión dramática tiene vital importancia dentro de una producción audiovisual, así sea una microestructura narrativa como la noticia. Pajoni, La Torre y Besada (2013: 167) responsabilizan al infoentretenimiento de ser el causante de la predominancia del drama y el espectáculo en las noticias.

"El infoentretenimiento en el plano de la producción del formato noticiero se caracteriza por la combinación de la información con el entretenimiento, con el propósito de atraer audiencia normalmente no interesadas en el seguimiento de las noticias en televisión, y transformando las noticias en espectáculo como 'piezas dramáticas o sensacionalistas"”.

El infoentretenimiento se ha posicionado al interior de las redacciones de los telediarios peruanos durante todo el proceso de producción del noticiero, desde la selección de los temas materia de coyuntura, el tratamiento de los hechos a cargo del reportero, la redacción del guion, al edición del material registrado por el equipo ENG y la presentación de la información televisiva en pantalla. Noticias de carácter policial, social, local, internacional y hasta político se narran con tintes de espectacularidad. Conflictos, dramas y emociones 
fuertes son el plato principal de la información audiovisual por lo que han mutado la agenda temática de los noticieros instaurándose como un frame imprescindible.

Diversos autores han abordado el proceso de fragmentación de la realidad que se realiza para presentar las noticias en formato audiovisual. La teoría del framing o "encuadre" permite establecer un código común de comprensión para emisores y receptores en la problematización de un conjunto de acontecimientos seleccionados, organizados y emitidos para comunicar (Pajoni, La Torre y Besada, 2013). Dado que para producir información, los profesionales suelen fragmentar la realidad en frames o "encuadres" que ameritan ser investigados y difundidos, en la actualidad, los hechos con alta carga emotiva, suelen ser frames importantes durante el proceso de producción de un noticiero.

Específicamente en el periodismo audiovisual, cuando un tema seleccionado causa gran impacto en los televidentes y genera rentabilidad a la pantalla del canal de televisión, se presenta un fenómeno conocido como key event o "evento clave". La aparición de un frame clave o key event desencadena en la búsqueda de temas similares por parte del medio de comunicación o de sus pares. Los acontecimientos virales propagados en las redes sociales suelen convertirse en un key event cuando se presentan como noticias dentro de un telediario.

Un ejemplo tangible dentro del periodismo audiovisual del Perú fue publicado también en el diario El Comercio en enero de 2015. Un usuario de la red social Facebook denunció haber encontrado un insecto en la pizza que ordenó a una cadena internacional. La fotografía se compartió en diversas plataformas virtuales y los canales de televisión hicieron eco de la denuncia que culminó en el retiro de dicha franquicia a nivel nacional. El frame empleado (para seleccionar este hecho y convertirlo en noticia) se volvió a utilizar en días posteriores dado que la prensa hizo públicas otras denuncias análogas en otros restaurantes e inclusive las autoridades realizaron operativos para comprobar la salubridad e higiene de los establecimientos que expenden alimentos.

La teoría del framing y sus variantes confirma que la información en televisión se selecciona con minuciosidad bajo estrictos cánones preestablecidos que, generalmente, auguran éxito en cuanto a índices de audiencia, ya que hacen referencia a la actualidad, proximidad, prominencia, curiosidad, expectativa, pasión, conflicto, consecuencias, entre otros aspectos generales de la noticia. Sin embargo, en los últimos años, se ha dado vital importancia al drama y la emotividad que deben tener las noticias. El reality (antes concebido como un formato del género entretenimiento) se abre espacio en los informativos diarios cada vez con más éxito; por lo que los productores de dichos espacios han volcado su atención a aquellas denuncias reales que se comparten en las plataformas virtuales de la Internet.

Peralta (2012) afirma que merced a las nuevas tecnologías y a la facilidad de intercambio de videos, se incrementan las noticias con imágenes que son aportadas por los telespectadores, las cuales enriquecen la información, pero que podrían devaluar el trabajo de los profesionales periodísticos. 


\subsection{Las fuentes periodísticas}

Otro aspecto que se ha visto afectado por la irrupción de la Internet en las redacciones de los telediarios es el contacto con las fuentes periodísticas, aquellas encargadas de dotar de información, datos o declaraciones al periodista sobre determinado frame. Más allá de las formas tradicionales de comunicación que tienen las fuentes informativas, tales como el rumor, la versión, el trascendido, la información confidencial, las oficinas de prensa y relaciones públicas, las conferencias de prensa (González, 1997), las entrevistas concertadas y las ruedas de prensa; la fuente de información ha encontrado en la comunicación por redes sociales un nuevo espacio para dar a conocer su punto de vista, hacerse escuchar y entrar en contacto con los periodistas.

Antes de que la presencia en redes sociales forme parte importante de la rutina de los ciudadanos, García (2000: 79) ya auguraba los cambios que iba a representar la masificación de la Internet en la producción periodística:

"Las nuevas tecnologías informáticas y telemáticas aplicadas al dominio audiovisual modifican los procesos de legitimación del quehacer profesional, amplían hasta límites insospechados el poder de acceder a las fuentes y, por tanto, limitan en esa misma medida los circuitos concéntricos que filtran la noticia, del punto de origen a las agencias, de estas a las redacciones y de las redacciones a las audiencias".

Hoy es posible afirmar que la Internet ha desechado por completo las barreras de espacio y distancia que existía normalmente entre los periodistas y algunas fuentes, gracias a que estas manejan cuentas personales o públicas en redes sociales como Facebook y Twitter. Asimismo, ha acelerado el contacto entre ambas y también ha facilitado de forma antes inimaginable el acceso del televidente a las misma fuentes que consulta el periodista para elaborar una noticia. Tanto el profesional de la información como el ciudadano común pueden contactarse con una fuente periodística mediante la comunicación por redes sociales.

\subsection{Tipología: fuentes periodísticas en el periodismo audiovisual}

Aunque existen diversas clasificaciones de fuentes periodísticas, para la presente investigación se ha formulado la siguiente tipología, basada en las aquellas fuentes con las que mantiene contacto el periodista audiovisual para la elaboración de noticias que formarán parte de un telediario.

- Agencias de noticias: son una de las fuentes principales a las que recurren los canales de televisión, debido a que proporcionan información e imágenes ya trabajadas para ser empleadas en el ejercicio del periodismo. Estas organizaciones se encargan de investigar, registrar e informar sobre hechos relevantes en cada país para posteriormente distribuirlos a sus clientes, que por lo general son medios de comunicación. Existen agencias de noticias a nivel nacional e internacional. 
- Fuentes oficiales: Mayoral (2009: 49) las define como "todas aquellas relativas al Gobierno central o a los ejecutivos autonómicos, ayuntamientos, sindicatos, patronal, partidos políticos y otro tipo de instituciones". Son fuentes que tienen el respaldo de alguna institución pública u oficial, son las voces autorizadas de determinada institución gubernamental o de la sociedad civil. Se consideran fuentes oficiales las instituciones y los agentes políticos que suelen pronunciarse a título personal pero pertenecen al sistema de poder.

- Fuentes no oficiales: a diferencia de las anteriores, no son voceros autorizados; al contrario, declaran a título personal sobre un tema específico: desde expertos y analistas hasta ciudadanos que presencian un hecho determinado o tienen implicancia en el mismo. Generalmente, el contacto con este tipo de fuentes no requiere intermediarios como agencias de relaciones públicas o departamentos de prensa. Por lo tanto, no es tan tedioso contactarlas como a las fuentes oficiales dado que no se encuentran al interior de una estructura de poder.

En esta clasificación se encuentran los protagonistas de la noticia: afectados por un desastre natural, personajes que encabezan una denuncia, el sindicado de cometer un delito en particular, la víctima de un caso de maltrato familiar, entre otros ejemplos. También se incluyen los testigos de los hechos, cuya importancia radica en que pueden explicar qué fue lo que realmente ocurrió respecto a determinada noticia, dado que aportan datos que sólo ellos poseen (Quesada, 2007) Gracias a los testigos, el periodista puede contrastar la información brindada con la que haya podido obtener de los protagonistas de la historia.

Tanto las fuentes oficiales como las no oficiales deben ser claramente identificadas por el reportero de televisión en el guion de la nota informativa que elabore y, por ende, deben ser totalmente reconocibles para la audiencia, es decir, tienen que ser atribuidas a su origen. Si bien existen formas de atribución en las cuales el periodista se reserva la identificación de las fuentes, lo ideal para el periodismo audiovisual es que se informe correctamente al televidente de quién proviene cierta información respecto a un hecho.

Sumado al valor de la atribución de las fuentes, el periodista debe verificar los datos que estas le proporcionan. Para ello, se vale del contraste de la versión otorgada por una fuente determinada con el de otras que tengan implicancia o conocimiento directo de la noticia con la finalidad de otorgarle credibilidad a la información propagada. Al respecto, Diezhandino (2009) considera que por más que el periodista se apoya en lo que dicen sus fuentes, sigue siendo el responsable de a qué fuentes acude. Agrega que en el periodismo, el resultado siempre depende de las fuentes que se utilicen, de las voces a las que se accede para elaborar el relato, de los datos documentales que se manejan, del conocimiento y comprensión de la historia o el tema que se intenta contar, de la búsqueda del contraste y la prueba de aquello que afirma la fuente; por ende, la credibilidad del relato periodístico está directamente relacionada con la búsqueda de la veracidad.

Las noticias que se desprenden de publicaciones en redes sociales como Facebook y Twitter no siempre son debidamente contrastadas $\mathrm{y}$, en algunas circunstancias, las denuncias 
provienen de fuentes que no son sencillas de ser identificadas, por lo que el reportero podría no cumplir con el deber de atribuir datos, denuncias o declaraciones a una fuente específica.

\subsection{Facebook y Twitter: la revolución de las redes sociales}

Internet ha pasado por diversas etapas antes de convertirse en el metamedio cuyas innumerables plataformas se explotan en la actualidad. El salto principal que hizo que la red de redes permita que los cibernautas tengan también una vida en el plano digital es la interactividad; gracias a la cual pueden comunicarse mediante herramientas digitales conocidas como redes sociales.

Carballar (2011) define a las redes sociales como un grupo de personas con algún tipo de interés común que se comunican online, cuyos participantes pueden o no conocerse personalmente, ya que lo que los une no tiene que ser una amistad existente, sino un interés común por algo (una afición, un tema social, coleccionismo, nueva tecnología, etc.). Quienes utilizan las redes sociales para comunicarse con sus pares no lo hacen únicamente para mantener contacto con personas a las que conocen personalmente. En muchas ocasiones, la relación que une a los contactos en redes sociales es un interés común, por lo que las redes sociales se emplean para intercambiar conocimientos online.

Otros autores como Alonso y Arébalos (2010) destacan que las redes sociales aglutinan millones de personas de todas partes del mundo dado que son servicios de entretenimiento y comunicación que también adquirieron la capacidad de movilizar personas hacia un hecho específico, ya sea una marcha a favor de una determinada política, un apagón mundial para ahorrar energía o la modificación de algún aspecto de la red social misma.

El entorno virtual de las redes sociales no es unidireccional. La interactividad que en los albores de la comunicación online sorprendía a usuarios y académicos, es imprescindible en la rutina diaria de los miembros de una comunidad. La comunicación en las redes sociales es horizontal. En ese sentido, los usuarios asumen el rol de consumidores, productores y distribuidores de contenidos, roles que desempeñan al mismo tiempo, por lo que se les denomina "prosumidores". Luchessi (2010) ejemplifica el desempeño de los prosumidores señalando que con varios clicks, cualquier persona, no necesariamente un periodista, puede crear un blog para contar historias con palabras o imágenes desde su propia perspectiva: sólo hace falta una computadora, una cámara fotográfica, un celular o alguna otra de las nuevas tecnologías infocomunicacionales. El contexto es amplio e interesante. Internet y sus plataformas sociales han permitido que los usuarios tengan el mismo poder que quienes manejan la información para publicar contenidos hipertextuales, razón por la cual se reconoce a este metamedio como el responsable de democratizar el acceso a la información a nivel mundial.

Precisamente, la teoría de los peers o "pares" describe el rol de los prosumidores que ya no se ven limitados a ser receptores de la información, sino que pueden volverse, a su vez, en emisores. Esta postura señala los peers funcionan como nodos del ecosistema 
de la Internet, donde comparten recursos y son iguales, descentralizados y, en ocasiones, anónimos. Además, pueden manifestarse de diversas maneras, por medio de un blog, un comentario, una compra, o redes sociales como Facebook y Twitter (Alonso y Arébalos, 2010). De esta manera, los peers no solo reciben información de los medios de comunicación tradicionales y los gatekeepers, también publican datos, denuncias, fotografías y videos que, con frecuencia, nutren a los medios de comunicación y tienen un impacto en los mismos.

La relación entre peers y medios de comunicación (especialmente los de formato audiovisual) es de retroalimentación. Circunstancia actual que deviene en un cambio en las rutinas productivas de los telediarios, de la jerarquización de los temas, el tratamiento de la información, el contacto con las fuentes periodísticas $\mathrm{y}$, según algunos autores como Noguera (2010), la desaparición de la agenda setting impuesta por los medios de comunicación.

\subsubsection{Facebook}

Facebook es una de las redes sociales más empleadas a nivel mundial que crece a una tasa de más de medio millón de usuarios por día, donde reina el aspecto personal que el usuario quiera compartir de sí mismo. Aguilar y Hung (2010) afirman que los conceptos de subjetividad e identidad adquieren nuevos matices en esta red social, dado que los usuarios diseñan (a plena conciencia) la imagen de sí mismo que quieren proyectar y con la cual se relacionarán con sus pares. De esta manera, tiene la posibilidad de re-crearse, re-diseñarse y convertirse en versiones, quizá, mejoradas de sí mismos. El perfil personal de Facebook es, entonces, una puesta en escena del yo interior que decide formular cada usuario, el cual tiene la posibilidad de crear en el ciberespacio un segundo ser con otra identidad, por lo que el usuario termina siendo dueño de su dimensión no virtual y de su otra dimensión o identidad virtual.

Esta bidimensionalidad se expresa mediante los perfiles personales, las cuentas oficiales, las publicaciones, comentarios, fotografías o videos compartidos por el usuario. Noguera (2010) resalta además la multimedialidad de Facebook que por su propia naturaleza permite una multitarea y remezcla de narrativas. Todo material compartido por un usuario en Facebook, desde perfiles personales o institucionales donde estos reflejan las características que consideran convenientes compartir, puede convertirse en insumo para la producción periodística de televisión y en material disponible para ser analizado, investigado y trabajado por el periodista.

\subsubsection{Twitter}

Situación similar ocurre con los tweets o publicaciones propaladas en la red social del ave azul. Twitter es el mayor exponente del microblogging dentro de las comunidades virtuales y su impacto se debe a que sus mensajes cortos de hasta 140 caracteres representan el triunfo de lo inmediato (Peña Jiménez y Pascual, 2013). En esta red de microblogging, cada usuario comparte mensajes que pueden incluir contenido multimedia o hipertextual con su 
comunidad de seguidores o followers. Políticos, deportistas, presidentes, personalidades del mundo del espectáculo, jefes de Estado y hasta el representantes de la Iglesia publican tweets expresando sus ideas, opiniones y posturas en esta red social.

Los usuarios o peers disfrutan de toda su potencia generadora de contenidos cuando interactúan en esta red social. Muchos de los temas que se discuten o los datos que se ventilan en Twitter, suelen convertirse en insumos para los medios de comunicación tradicionales. Apenas ocurre un acontecimiento de importancia en una ciudad determinada, los peers empiezan a publicar aquello que observan (fotografías), aquello que critican del hecho en sí e inclusive sus impresiones respecto al mismo: todo esto en tiempo real, mientras se vienen suscitando los acontecimientos.

Asimismo, en plataformas como Twitter, el uso de la interactividad es o que define la predominancia de los usuarios en la esfera pública-online. Aquellos twitteros que comparten más información, que participan de los foros o debates y que desatan polémica son los que congregan más seguidores. Esta interactividad no solo es vital para el funcionamiento de la red de microblogging Twitter y la relación entre sus usuarios. Además, se explota en el ámbito periodístico. Según Peralta (2012), Twitter está transformando la accesibilidad de los profesionales a los protagonistas de las noticias, dado que el acceso a las fuentes de información y a los protagonistas de la actualidad es básico para los profesionales de la comunicación. Los periodistas pueden encontrar a los protagonistas de las noticias en Twitter, quienes ahora se reservan la exclusividad de sus mensajes para esta red social, desde la cual se comunican sus seguidores, así como la opinión pública en general, que termina leyendo las posturas que los protagonistas de las noticias publican en su cuenta de Twitter y que son replicadas en los medios tradicionales.

\section{Análisis y discusión de resultados}

Una vez obtenidos los datos en el trabajo de campo tras aplicar la encuesta (con cada uno de los ítems o reactivos) a los periodistas del noticiero "ATV Noticias" y cumpliendo con las tareas de la estadística descriptiva se pudo resumir, ordenar y presentar la información en diferentes tablas de frecuencias (absoluta, relativa y acumulada) y gráficas que se presentan a continuación. Respecto a la variable "periodismo televisivo", se consultó si los periodistas encuestados consideraban que la pauta final del noticiero incluía noticias que se han elaborado empleando insumos (comentarios, fotografías, videos) publicados en las redes sociales. 
Figura 2: Resultados respecto a la pauta del noticiero.

\begin{tabular}{|l|l|l|l|l|l|}
\hline \multicolumn{6}{|c|}{$\begin{array}{l}\text { ¿La PAUTA final del noticiero incluye noticias que se han elaborado empleando } \\
\text { insumos (comentarios, fotografias, videos) publicados en las redes sociales? }\end{array}$} \\
& Frecuencia & Porcentaje & $\begin{array}{l}\text { Porcentaje } \\
\text { válido }\end{array}$ & $\begin{array}{l}\text { Porcentaje } \\
\text { acumulado }\end{array}$ \\
\hline \multirow{4}{*}{ Válidos } & En desacuerdo & 1 & 3.3 & 3.3 & 3.3 \\
\cline { 2 - 6 } & Indeciso & 2 & 6.7 & 6.7 & 10.0 \\
\cline { 2 - 6 } & $\begin{array}{l}\text { Parcialmente de } \\
\text { acuerdo }\end{array}$ & 11 & 36.7 & 36.7 & 46.7 \\
\cline { 2 - 6 } & De acuerdo & 16 & 53.3 & 53.3 & 100.0 \\
\cline { 2 - 6 } & TOTAL & 30 & 100.0 & 100.0 & \\
\hline
\end{tabular}

Fuente: Elaboración propia.

Figura 3: Resultados respecto a la pauta del noticiero.

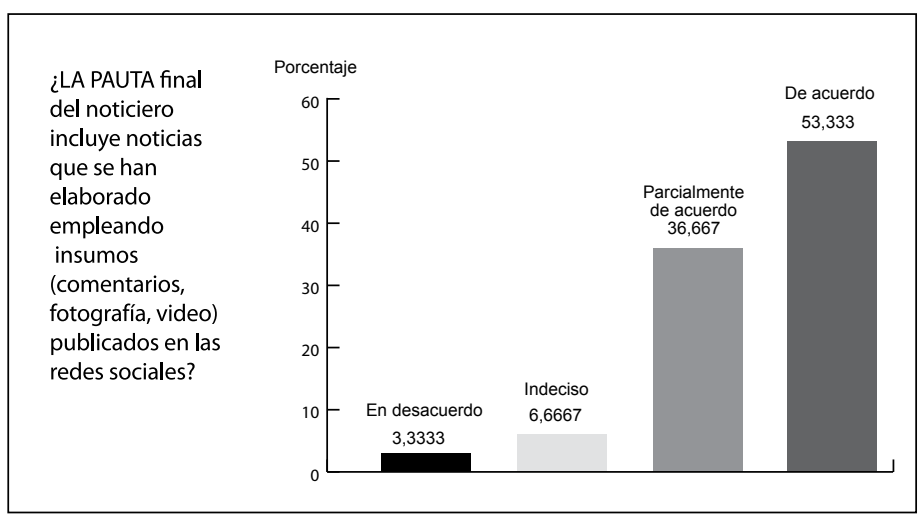

Fuente: Elaboración propia.

Asimismo, al abordar la misma variable, el 76.66\% de los encuestados respondieron estar de acuerdo con que la selección de material audiovisual a emplear para el desarrollo de una nota informativa puede nutrirse con los videos compartidos en redes sociales; el $20 \%$ mencionó estar parcialmente de acuerdo y el 3.33\% completamente en desacuerdo. Muchos de los videos caseros que los usuarios de redes sociales registran desde sus teléfonos celulares (y que luego comparten en redes sociales) se incluyen en las noticias en formato audiovisual para darle mayor credibilidad a la historia narrada y adicionarle el punto de vista de los protagonistas o testigos.

Finalmente, según la información recogida, el 70\% de los encuestados respondieron estar de acuerdo con que las redes sociales facilitan que el periodista obtenga mayor acceso a noticias sobre el tema materia de cobertura, el $23.33 \%$ mencionó estar parcialmente de 
acuerdo y el 3.33\% indeciso y completamente en desacuerdo. Mediante las redes sociales, el periodista entra en contacto con otros medios de comunicación (regionales, nacionales y hasta internacionales) los que le servirán como fuente de consulta al momento de elaborar una información y le permitirán contrastar los datos que haya podido recoger en su labor periodística.

Al abordar las preguntas basadas en la variable "fuentes periodísticas", se consultó a los periodistas si consideraban que la comunicación por redes sociales facilita el contraste de la información que brindan las fuentes periodísticas.

Figura 4: Resultados respecto al contraste de fuentes periodísticas.

\begin{tabular}{|l|l|l|l|l|l|}
\hline \multicolumn{7}{|c|}{$\begin{array}{c}\text { ¿Cree Ud. que la comunicación por redes facilita el CONTRASTE de } \\
\text { la información que brindan las fuentes periodísticas? }\end{array}$} \\
\hline \multirow{4}{*}{ Válidos } & Frecuencia & Porcentaje & $\begin{array}{l}\text { Porcentaje } \\
\text { válido }\end{array}$ & $\begin{array}{l}\text { Porcentaje } \\
\text { acumulado }\end{array}$ \\
\hline \multirow{4}{*}{} & En desacuerdo & 2 & 6.7 & 6.7 & 6.7 \\
\cline { 2 - 7 } & Indeciso & 4 & 13.3 & 13.3 & 20.0 \\
\cline { 2 - 7 } & $\begin{array}{l}\text { Parcialmente de } \\
\text { acuerdo }\end{array}$ & 12 & 40.0 & 40.0 & 60.0 \\
\cline { 2 - 7 } & De acuerdo & 12 & 40.0 & 40.0 & 100.0 \\
\cline { 2 - 6 } & TOTAL & 30 & 100.0 & 100.0 & \\
\hline
\end{tabular}

Fuente: Elaboración propia.

Figura 5: Resultados respecto al contraste de fuentes periodísticas.

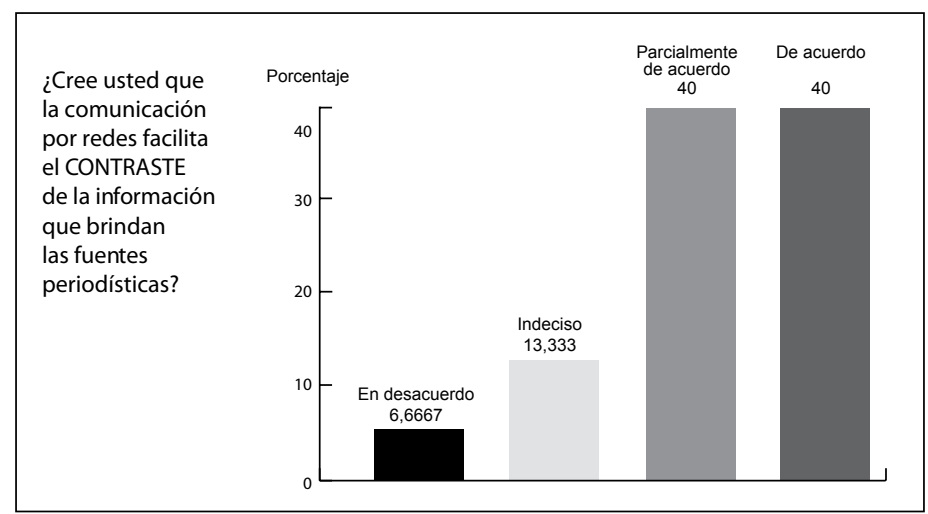

Fuente: Elaboración propia.

El $53.33 \%$ de los encuestados respondieron estar parcialmente de acuerdo con que el acceso a la información (que publican las fuentes periodísticas en sus cuentas personales de redes sociales) facilita su verificación e identificación; el 26.66\% mencionó estar de 
acuerdo y el $10 \%$ indeciso y en desacuerdo. El periodista suele emplear las redes sociales para contrastar lo declarado por una fuente específica con la información que la misma comparte y publica en sus cuentas de Facebook y Twitter.

Respecto a la comunicación por redes sociales (específicamente el proceso de intercambio de información y retroalimentación ocurrido en Facebook) el 56.66\% de los encuestados respondieron estar parcialmente de acuerdo con que los perfiles personales de Facebook (de los personajes involucrados en una noticia) se pueden emplear como fuente de información; el $33.33 \%$ mencionó estar de acuerdo y el $10 \%$ en desacuerdo. Esto se debe a que las publicaciones en Facebook son de carácter personal y, por ende, tanto las fotografías como los datos compartidos se utilizan como información de primera mano proveniente de la fuente.

Figura 6: Resultados respecto a los perfiles personales de Facebook.

\begin{tabular}{|l|l|l|l|l|l|}
\hline \multicolumn{6}{|c|}{$\begin{array}{l}\text { ¿Está Ud. de acuerdo en que los perfiles PERSONALES de Facebook de los personajes } \\
\text { involucrados en una noticia se pueden emplear como fuente de información? }\end{array}$} \\
\hline \multirow{4}{*}{} & Frecuencia & Porcentaje & $\begin{array}{l}\text { Porcentaje } \\
\text { válido }\end{array}$ & $\begin{array}{l}\text { Porcentaje } \\
\text { acumulado }\end{array}$ \\
\hline \multirow{4}{*}{ Válidos } & En desacuerdo & 3 & 10.0 & 10.0 & 10.0 \\
\cline { 2 - 6 } & $\begin{array}{l}\text { Parcialmente de } \\
\text { acuerdo }\end{array}$ & 17 & 56.7 & 56.7 & 66.7 \\
\cline { 2 - 6 } & De acuerdo & 10 & 33.3 & 33.3 & 100.0 \\
\cline { 2 - 6 } & TOTAL & 30 & 100.0 & 100.0 & \\
\hline
\end{tabular}

Fuente: Elaboración propia.

Figura 7: Resultados respecto a los perfiles personales de Facebook

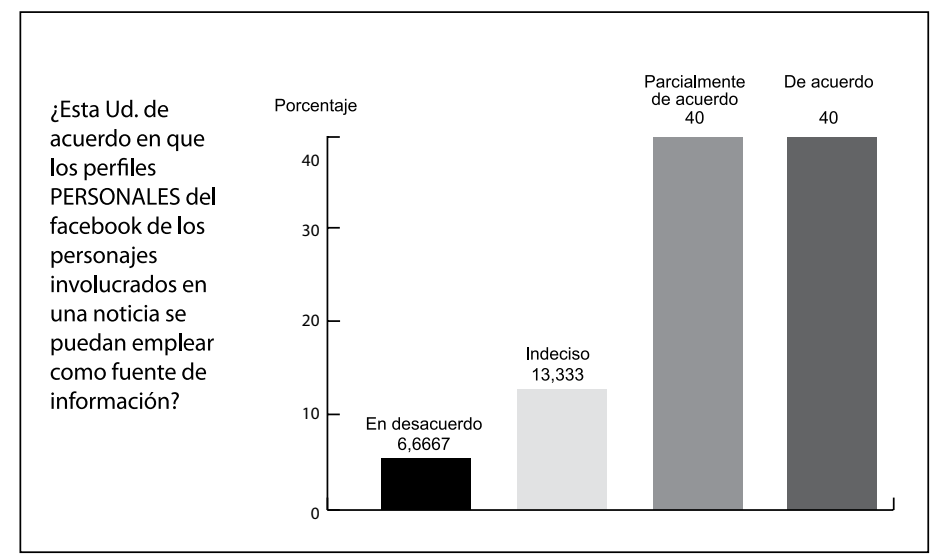

Fuente: Elaboración propia. 
El $53.33 \%$ de los encuestados respondieron estar parcialmente de acuerdo con que la retroalimentación generada en Facebook (sobre un tema específico) aporta datos extra para el periodista que cubre dicha información; el 36.66\% mencionó estar de acuerdo, el $6.66 \%$ en desacuerdo y el $3.33 \%$ indeciso. Los comentarios, publicaciones y demás interacciones entre usuarios de Facebook complementan la información obtenida por el periodista respecto a la noticia materia de cobertura.

Sobre la retroalimentación generada en Twitter, se consultó a los periodistas si las actualizaciones constantes de los mensajes de Twitter permiten que el reportero obtenga datos de primera mano de forma inmediata. Las respuestas se muestran en el siguiente gráfico.

Figura 8: Resultados sobre las actualizaciones en Twitter.

\begin{tabular}{|c|c|c|c|c|c|}
\hline \multicolumn{6}{|c|}{$\begin{array}{l}\text { ¿Las ACTUALIZACIONES constantes de los mensajes de Twitter permiten } \\
\text { que el reportero obtenga datos de primera mano de forma inmediata? }\end{array}$} \\
\hline & & Frecuencia & Porcentaje & $\begin{array}{l}\text { Porcentaje } \\
\text { válido }\end{array}$ & $\begin{array}{l}\text { Porcentaje } \\
\text { acumulado }\end{array}$ \\
\hline \multirow{4}{*}{ Válidos } & Indeciso & 2 & 6.7 & 6.7 & 6.7 \\
\hline & $\begin{array}{l}\text { Parcialmente de } \\
\text { acuerdo }\end{array}$ & 10 & 33.3 & 33.3 & 40.0 \\
\hline & De acuerdo & 18 & 60.0 & 60.0 & 100.0 \\
\hline & TOTAL & 30 & 100.0 & 100.0 & \\
\hline
\end{tabular}

Fuente: Elaboración propia.

Figura 9: Resultados sobre las actualizaciones en Twitter.

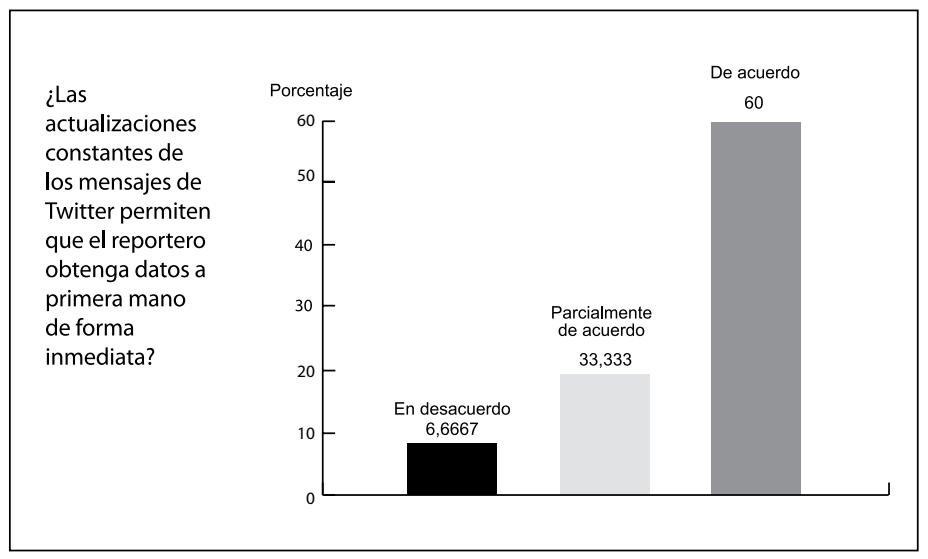

Fuente: Elaboración propia. 
El $73.33 \%$ de los encuestados respondieron estar de acuerdo con que la multimedialidad de los mensajes de Twitter facilita que el periodista acceda a más datos, artículos, videos y fotografías respecto al tema materia de cobertura y el $26.66 \%$ parcialmente de acuerdo. Los tweets suelen contener hipervínculos; por lo tanto, el periodista puede acceder a mayor cantidad de información en la web gracias a los documentos hipertextuales compartidos por su grupo de contactos en esta red social.

\section{Conclusiones}

Las principales conclusiones a las cuales se arribó en esta investigación han sido extraídas de cada una de las mediciones realizadas con respecto al periodismo televisivo, a las fuentes periodísticas y a la comunicación por redes sociales (Facebook y Twitter) del noticiero "ATV Noticias".

Se ha determinado que el periodismo televisivo se relaciona significativamente con las fuentes periodísticas y la comunicación por redes sociales (Facebook y Twitter) en el noticiero "ATV Noticias". La comprobación de esta hipótesis principal fue realizada aplicando la prueba no paramétrica de chi - cuadrado, teniendo como resultado a p.valor = 0,000 y como este valor es menor que 0.05 entonces se rechaza la $\mathrm{H}_{\mathrm{o}}$.

Es así que el periodismo televisivo se relaciona significativamente con las fuentes periodísticas en el noticiero "ATV Noticias". Para el contraste de esta hipótesis específica también se utilizó la prueba no paramétrica de chi cuadrado, la misma que tiene como resultado lo siguiente: $\mathrm{p}=0,000<0.05$, rechazándose así la $\mathrm{H}_{\mathrm{o}}$. De igual manera, se ha demostrado que el periodismo televisivo se relaciona con la comunicación por redes sociales en el noticiero "ATV Noticias". La verificación de esta hipótesis específica se realizó utilizando la prueba no paramétrica de chi cuadrado, la misma que tiene como resultado lo siguiente: $\mathrm{p}=0,001$ es menor al nivel de significación de 0.05 , rechazándose así la $\mathrm{H}_{\mathrm{o}}$.

\section{Fuentes consultadas}

Aced, C. y otros (2009). Visibilidad. Barcelona: Gestión 2000.

Aguilar, E. y Hung, E. (2010). "Identidad y subjetividad en las redes sociales virtuales". Zona Próxima, núm. 12, pp. 197-207.

Alonso, G. y Arébalos, A. (2010). La Revolución horizontal, el poder de la comunicación en manos de la gente. Lima: USMP.

Carballar, J. (2011). Twitter. Marketing personal y profesional. México D. F.: Alfaomega.

Diezhandino, M. (2009). Criterio noticioso. Madrid: Pearson Educación. 
Faerman, J. (2009). Faceboom. El nuevo fenómeno de masas Facebook. Buenos Aires: Ediciones B.

García, J. (2000). Información audiovisual [vol 1-2]. Madrid: Paraninfo.

González, S. (1997). El ejercicio del periodismo. México D. F.: Editorial Trillas.

Luchessi, L. (comp.) (2010). Nuevos escenarios detrás de las noticias. Buenos Aires: La Crujía.

Marín, C. (2006). Periodismo audiovisual. Barcelona: Gedisa.

\section{Mayoral, J.}

_(2013). Redacción periodística. Medios, géneros y formatos. Madrid: Síntesis.

_(2009). El uso periodístico de las fuentes en radio y televisión. Madrid: Universidad Camilo José Cela.

Noguera, J. (2010). "Redes sociales como paradigma periodístico. Medios españoles en Facebook". Extraída el 27/VI/2016 desde http:/www.redalyc.org/articulo. oa? id=81915723013\#

Pajoni, H.; La Torre, L. y Besada, M. (2013). "Noticieros en Argentina: la representación de la actualidad en las encrucijadas políticas”. Revista de comunicación, núm. 12, pp. 152-181.

Peña Jiménez, P. \& Pascual, A. (2013). "Redes sociales en la radio española. Facebook, Twitter y Community Management". Revista de Estudios de Comunicación ZER. Vol. 18, núm. 35. pp. 123-144. Extraída el 27/VI/2016 desde http://www.ehu.eus/zer/hemeroteca/ pdfs/zer35-06-pena.pdf

Peralta, M. (2012). Teleinformativos. La noticia digital en televisión. Barcelona: Editorial UOC.

Pérez, G. (2010). Informar en la e-televisión. Navarra: Ediciones Universidad de Navarra.

Pintado, T. y Sánchez, J. (2012). Nuevas tendencias en comunicación. Madrid: Esic.

Quesada, M. (2007). Periodismo de sucesos. Madrid: Síntesis.

Saldaña, W. (2013). Medios, redes sociales y blogs en el ciberespacio. Lima: USMP. 